\title{
Web Usage Mining: A Concise Survey on Tools and Applications
}

\author{
Arun Kumar Singh ${ }^{1}$ \\ (Associate Professor)
}

\author{
Dheeraj Sharma ${ }^{1}$ \\ (Assistant Professor) \\ IIMT Engineering College, Meerut ${ }^{1}$
}

\author{
Avinav Pathak \\ (Lecturer)
}

\begin{abstract}
Web usage mining focuses on techniques that might predict user behavior whereas the user interacts with the net. It tries to create sense of the info generated by the net surfer's sessions or behaviors. There has been an effort to supply a summary of the state of the art within the analysis of internet usage mining, whereas discussing the foremost relevant tools obtainable within the sphere likewise because the niche needs that this form of tools lack. It offers an outlook on the prevailing tools, their specialized focus with reference to the practical objectives and also the would like for a additional comprehensive new entrant during this sphere within the light-weight of this state of affairs. In the end, the paper are finished by listing some challenges and future trends during this analysis space. Overall the main target of the paper are to gift a survey of the recent developments during this space that is obtaining an excessive amount of attention from internet development arena.
\end{abstract}

\section{KEYWORDS}

Artificial Intelligence, Data Mining, Information overload, Navigation Patterns, Web Log, Web Mining, Web Personalization, Web site structure, Web usage mining,

\section{INTRODUCTION}

Web mining could be a immensely fascinating analysis topic which mixes two of the activated analysis areas: data processing and World Wide internet. With the large quantity of data out there on-line, the planet Wide internet could be a fertile space for data processing analysis. the online mining analysis relates to many analysis communities, like information, info retrieval, and AI. the planet Wide internet (Web) could be a fashionable and interactive medium to circularize info nowadays. the online is big, diverse, and dynamic and so raises the quantifiability, multimedia system knowledge, and temporal problems severally. it had been Oren
Etzioni who initial coined the term internet mining in his paper in 1996. Etzioni starts by creating a hypothesis that the data on the online is sufficiently structured and descriptions the subtasks of internet mining [1]. His paper describes the online mining processes.

Web data processing are often outlined because the discovery and analysis of helpful info from the computer network knowledge. Since then, there are many works round the survey of information mining on the online though internet mining puts down the roots deeply in data processing, it's not appreciate data processing. The unstructured feature of internet knowledge triggers a lot of quality within the method of internet mining. A degree exponential growth in on-line info combined with the virtually unstructured internet knowledge necessitates the event of powerful nevertheless computationally economical internet data processing tools. Web mining is that the use of data of knowledge of mining techniques to mechanically discover and extract information from internet documents and services [1]. This space of analysis is therefore vast nowadays part owing to the interests of assorted analysis communities, the tremendous growth of data sources out there on the online and therefore the recent interest in ecommerce. later, Madria, et al. [2] and Jorge Luis Borges and Levene, categorised internet mining into 3 areas of interest supported that a part of the online to mine: website mining, internet structure mining, and internet usage mining. In follow, the 3 internet mining tasks higher than might be employed in isolation or combined in associate degree application, particularly in website and structure mining since the online documents may additionally contain links. as an example, Chakrabarti et al. [4] uses as website the terms in a very document's link neighborhood and as internet structure the links from its neighbors, to classify sites. Joachims, Freitag, and Mitchell use website and usage to create a computer code tour agent for helping users browsing an online website. 


\section{WEB USAGE MINING: AN OVERVIEW}

Web usage mining focuses on techniques that would predict user behavior whereas the user interacts with the Web. As mentioned before, the deep-mined information during this class are the secondary information on the online because the results of interactions. These information might vary terribly wide however usually we tend to might classify them into the usage information that reside within the internet purchasers, proxy servers and servers [6]. the Web usage mining method may be classified into 2 ordinarily used approaches [3]. the Web usage mining method may be considered a three-phase method, consisting of the info preparation, pattern discovery and pattern analysis phases (See figure one, Mobasher et al. [7]). within the 1st part, diary information are preprocessed so as to spot users, sessions, page views, and so on. within the second part, applied math strategies, yet as data processing strategies (such as association rules, successive pattern discovery, clustering, and classification) are applied so as to notice fascinating patterns. These patterns are keep so they'll be additional analyzed within the third part of the online usage mining method [8].

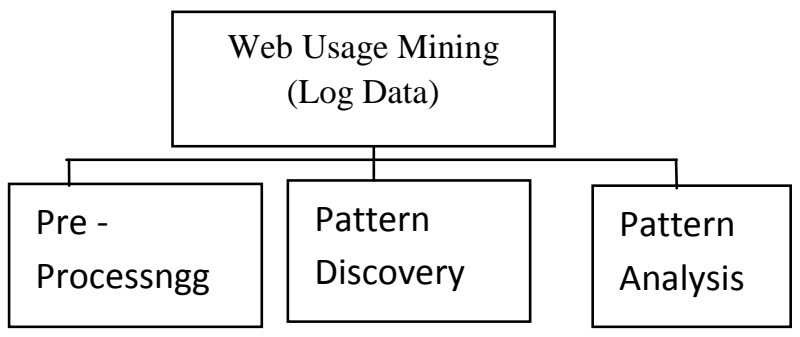

Fig 1.

\section{RELATED RESEARCH}

There are some works around content mining, and structure mining,that supported the analysis of information mining and knowledge Retrieval, data Extraction, and computing. But, within the web usage mining analysis space, many teams did distinguished work. From the business and applications purpose of read, data obtained from the net usage patterns may be directly applied to expeditiously manage activities associated with e business, e-services, e-education so on. correct net usage data might facilitate to draw in new customers, retain current customers, improve cross marketing/sales, effectiveness of promotional campaigns, track effort customers and realize the foremost effective logical structure for his or her net area [14]. User profiles may be engineered by combining users' navigation methods with alternative information options, like page viewing time, link structure, and page content. The last comprehensive survey on net usage mining has been done by Koutri, Avouris, and Daskalaki. Pierrakos et al. [16] earlier explored the realm of net usage mining as a tool for the personalization method. Eirinaki, and Vazirgiannis [8] conjointly conferred a wonderful survey upon a overall space of Web Ming dynasty for personalization. Kosala and Blockeel [21] explored the terms of net mining and also the connected analysis space earlier in their work. Since then net mining analysis has been somewhat copied within the annual
The first approach maps the usage information of the online server into relative tables before data processing technique is performed. The second approach uses the $\log$ information directly by utilizing special preprocessing techniques. As is true for any typical data processing applications, the problems of information quality and pre-processing are important here. The everyday drawback is distinctive among distinctive users, server sessions, episodes, etc. within the presence of caching and proxy servers [7,9]. In general, typical data processing strategies may be wont to mine the usage information once the information are pre-processed to the specified kind [6]. However, modifications of the everyday data processing strategies are used like composite association rules [3], a standard sequence discovery rule Midas [10] and machine-readable text probabilistic grammars. the web usage information might even be pictured with graphs [10]. typically internet usage mining strategies uses some background or domain data like navigation templates, web page, website topology, idea hierarchies, and grammar constraints $[10,11]$. The applications of internet usage mining may be classified into 2 main categories: On one hand, learning a user profile or user modeling in adaptable interfaces (personalized) and learning user navigation patterns (impersonalized). Web users would have an interest in, among others, techniques that would learn their data needs and preferences, that is user modeling probably combined with web page mining. On the opposite hand, data suppliers would have an interest in, among others, techniques that would improve the effectiveness of the data on their websites by adapting the online site style or by biasing the user's behavior towards satisfying the goals of the location. In different words, they are interested in learning user navigation patterns. Then the learned data may be used for applications like personalization (at an internet website level), system improvement, website modification, business intelligence, and usage characterization WebKDD workshop. WebKDD 2008 was the tenth of a victorious series of Workshops. Launched in 1999 by Brij Masand and Myra Spiliopoulou, the primary workshop of the series WebKDD 1999 invited contributions on "Web usage mining". within the ten years that followed, the scope of WebKDD was broadened to hide the rising KDD topics on the net.

Along with this, historical study has been conducted by many researchers that square measure specialised in net mining techniques and a number of other frameworks have already been explored. The results of these researches has cause the event of heap of applications within the space of net mining and that they square measure with success applied in business and ecommerce domain areas. Few landmark researches are followed here. Cooley et al. [18] projected a framework for net mining victimisation varied net mining task and enforced a epitome particularly Web miner. it's enforced by applying a framework that perform cluster analysis on association rules and ordered pattern discovery. Zaiane projected the thought of a way to implement the OLAP technique on the Web Usage mining. Their works on the multimedia system information conjointly provided a valuable answer for content mining. Spiliopoulou [12] centered on the applications of the usage mining. Cooley [20] in University of Gopher State did in-depth analysis to any or all the procedure of usage mining. They 
projected a mining epitome net laborer and derived a system net SIFT to perform the usage mining, that is comparatively sensible. Lee and Liu projected intelligent multi-agent based atmosphere called intelligent Java Development atmosphere (iJADE) to supply an integrated and intelligent agent based platform within the e-commerce atmosphere on web looking thus applying of intelligent agent for serving to users is applied in varied applications and not solely in e-commerce atmosphere. Mobasher et al. projected a good and ascendable techniques for net personalization supported association rule discovery from usage information. Toolan and Kushmerick [23] projected techniques supported net usage mining to deliver customized web site Maps that square measure specialised to the interest of every individual traveler. Applying the agent technology has improved the performance of net mining compared to ancient approach like information approach. On the opposite hand, Eirinaki and Vazirgiannis [8] developed a module that includes an online personalization system regarding the net usage mining module. Also, Lu, Dunham, and Meng [20] later projected a way to get vital Usage Patterns (SUP) and used them to accumulate vital "user most well-liked steering trails". Falkowski et al. [25] projected 2 approaches to investigate the evolution of 2 differing kinds of on-line communities on the amount of subgroups. Labroche, Lesot, Associate in Nursingd Yaffi introduces a replacement tool for net usage mining and visual image that depends on the biomimetic relative agglomeration algorithmic program supported normalcy computation to supply an economical visual image of the activity of users on a web site. Khalil, Li and Wang recently endeavors to supply an improved web content prediction accuracy by employing a novel approach that involves group action agglomeration, association rules and Andre Markoff models per some constraints. Experimental results prove that this integration provides higher prediction accuracy than victimisation every technique one by one. Tao, Hong and $\mathrm{Su}$ [28] explore a replacement information supply referred to as intentional browsing information (IBD) for doubtless rising the effectiveness of WUM applications.Nasraoui et al. [29] gift Associate in Nursing approach for locating and chase evolving user profiles and enrich it with specific data gathered from diary information. along with this profiles are provides alternative domain specific data and a validation strategy is understood to assess the standard of the strip-mined

\section{APPLICATION AND TOOLS}

Web mining for usage pattern is that the key to get promoting intelligence in e-commerce. It helps chase of general access pattern, personalization of Web usage link or online page and customizing adjustive sites. It will disclose the properties and inter-relationship between potential customers, users and markets, thus on improve net performance, on-line promotion and personalization activities [39]. There square measure several standard programs for usage pattern mining (see Table 1). journal Mining [6] uses KDD techniques to know general access patterns and trends to shed light-weight on higher structure and grouping of resource suppliers. For e.g., net jack [9] discovers association rules and successive patterns mechanically from server access logs, business code net Analyst by Megaputer learns the interests of the guests, supported their interaction with the web site. profiles. Masseglia et al. [30] propose to perform a particular data mining process to extract frequent behaviours by discovering the densest periods. Such amounts square measure the one having a minimum of one frequent ordered pattern for the set of users connected to the net web site in this period. Khiribi, Jemni, \&amp; Nasraoui build a personalised recommendation engine that aim to figure on-line automatic recommendations to a lively learner supported his recent navigation history. This can be done by exploiting similarities and dissimilarities among user selections and among the contents of the resources. David et al. [32] projected a probabilistic model for an online website that uses the entropy of a Markoff process so as to figure the user navigation patterns from the log information. Most of the analysis within the space of net usage mining concentrate on the algorithmic program whereas disregarding the sort of information on that the algorithmic program are applied. Hasan, Mudur and Shiri [33] projected a straightforward nevertheless effective technique referred to as generalization of net sessions that replaces actual pageclicks with their general ideas. This approach is extremely effective in overcoming the matter of measurability with regard to net usage mining. Dai and Mobasher emphasised the necessity to web usage and content data, by enhancing the data within the net usage logs with linguistics derived from the content of the net site's pages. Rao, Kumari, and Raju, [35] developed algorithmic program supported association rule mining with progressive technique to suit the dynamically dynamical log state of affairs that is a lot of economical that running variety of scans of information. Kumar and Rukmani [36] compared however Apriori algorithmic program and Frequent Pattern Growth algorithmic program take issue in terms of memory usage and time usage whereas discovering the net usage patterns of internet sites from the server log files. Thakre and Gawali stress the importance of an the effective and complete preprocessing of access stream before actual mining method may be performed. This might considerably improve the automated discovery of important pattern and relationships from access stream of user. Senkul and Salin [38] worked upon investigation the impact of linguistics data on the patterns generated for net usage mining within the type of frequent sequences. The frequent steering patterns square measure composed of metaphysics instances rather than web content addresses.

Clementine and DB2 Intelligent jack for information square measure 2 general data processing tools, which might be used for net usage mining with appropriate information preprocessing.

There are many business computer code tools (see Table 1) that would give internet usage statistics. These stats may well be helpful for internet directors to urge a way of the particular load on the server. However, the applied mathematics knowledge obtainable from the conventional diary knowledge files or maybe the data given by internet trackers may solely provide the data expressly due to the character and limitations of the methodology itself. Generally, one may say that the analysis depends on 3 general sets of knowledge given a current focus of attention: (1) past usage patterns; (2) degree of shared content; and (3) repose memory associative link structures. Once browsing through a number of the options of the most effective trackers obtainable it's simple to conclude that instead of 
generating applied mathematics knowledge and texts they very don't facilitate to and far purposeful data for tiny internet servers, the usage statistics provided by standard computing device trackers is also equal to analyze the usage pattern and trends, but because the size and complexness of the information will increase, the statistics provided by existing diary file analysis tools might prove inadequate and additional intelligent data mining techniques are going to be necessary. Maier and Reinartz [40] conducted a comprehensive analysis of Web Usage Analysis Tools in their analysis.

\begin{tabular}{|c|c|c|c|c|}
\hline S.No. & Tool & Researcher/Company & Feature & Function \\
\hline 1. & ArchCollect & $\begin{array}{l}\text { Esmin et.al } \\
2005\end{array}$ & $\begin{array}{l}\text { It uses fast semantic } \\
\text { interaction acquisition }\end{array}$ & $\begin{array}{l}\text { To monitor users' } \\
\text { algorithms and form a } \\
\text { dimensional cube of } \\
\text { interactions in web } \\
\text { information directly } \\
\text { which serve as input to } \\
\text { an IR media. }\end{array}$ \\
\hline 2. & i-Miner & $\begin{array}{l}\text { Abraham et al. } \\
2003\end{array}$ & $\begin{array}{l}\text { To optimize the } \\
\text { concurrent architecture of } \\
\text { a fuzzy } \\
\text { clustering algorithm (to } \\
\text { discover data clusters). }\end{array}$ & $\begin{array}{l}\text { Pattern Discovery and } \\
\text { trend analysis from web } \\
\text { usage data }\end{array}$ \\
\hline 3. & AWUSA & $\begin{array}{l}\text { Tiedtke et al. } \\
2002\end{array}$ & $\begin{array}{lr}\text { A framework based } & \text { on } \\
\text { combination } & \text { of } \\
\text { information } & \text { architecture, } \\
\text { automated } & \text { usability } \\
\text { evaluation. } & \end{array}$ & $\begin{array}{l}\text { Automated website } \\
\text { evaluation and web } \\
\text { mining techniques for } \\
\text { data gathering analysis. }\end{array}$ \\
\hline 4. & i-Jade web & $\begin{array}{l}\text { Lee and Liu } \\
2001\end{array}$ & $\begin{array}{l}\text { To use Agent technology, } \\
\text { together with Web } \\
\text { mining technology, to } \\
\text { automate a series of } \\
\text { applications. }\end{array}$ & $\begin{array}{lr}\text { E-commerce } & \text { Miner } \\
\text { product search } & \text { and } \\
\text { selection activities } & \end{array}$ \\
\hline 5. & Web Quilt & $\begin{array}{l}\text { Hong et.al. } \\
2001\end{array}$ & $\begin{array}{l}\text { Web logging and } \\
\text { visualization system that } \\
\text { helps web } \\
\text { design teams capture } \\
\text { usage traces which can } \\
\text { analyze the collected data. }\end{array}$ & To run usability tests \\
\hline 6. & KOINOTITES & $\begin{array}{l}\text { Pierrakos et al. } \\
2000\end{array}$ & $\begin{array}{l}\text { A system which uses data } \\
\text { mining techniques for } \\
\text { the construction of user } \\
\text { communities on the Web. }\end{array}$ & Personalization \\
\hline 7. & INSITE & $\begin{array}{l}\text { Shahabi et al. } \\
2000\end{array}$ & $\begin{array}{l}\text { To generate user profiles } \\
\text { in real time through the } \\
\text { use of a unique } \\
\text { Connectivity Matrix } \\
\text { Model (CM- model) }\end{array}$ & $\begin{array}{l}\text { INSITE acquisition and } \\
\text { show the efficacy and } \\
\text { essence of the captured } \\
\text { information }\end{array}$ \\
\hline 8. & SEWeP & $\begin{array}{l}\text { Eirinaki M. et al. } \\
2000\end{array}$ & $\begin{array}{l}\text { Developed as a system } \\
\text { that makes use of both the } \\
\text { usage logs and the } \\
\text { semantics of a Web site. }\end{array}$ & Activity log data. \\
\hline
\end{tabular}




\begin{tabular}{|c|c|c|c|c|}
\hline 9. & Web Tool & $\begin{array}{l}\text { Masseglia et al. } \\
2000\end{array}$ & $\begin{array}{l}\text { It uses sequential pattern } \\
\text { mining which relies on } \\
\text { PSP an algorithm } \\
\text { developed by the authors. }\end{array}$ & Usage Profiling \\
\hline 10. & Web Sift & $\begin{array}{l}\text { Cooley et al. } \\
1999\end{array}$ & $\begin{array}{l}\text { System uses the content } \\
\text { and structure information } \\
\text { from a website in order to } \\
\text { identify interesting } \\
\text { frequent item sets }\end{array}$ & $\begin{array}{l}\text { To mine interesting data } \\
\text { from web data. }\end{array}$ \\
\hline 11. & MiDAS & $\begin{array}{l}\text { Buchner at al. } \\
1998\end{array}$ & $\begin{array}{l}\text { It introduces a new } \\
\text { algorithm called MiDAS } \\
\text { that } \\
\text { traditional extends } \\
\text { discovery with a wide } \\
\text { range of web-specific } \\
\text { features. }\end{array}$ & Pattern Discovery \\
\hline 12. & Web Usage Miner & $\begin{array}{l}\text { Spilioupoulou et al. } \\
1998\end{array}$ & $\begin{array}{l}\text { It exploits an innovative } \\
\text { aggregated } \\
\text { server log. It discovers } \\
\text { patterns comprised of not } \\
\text { form of graphs. }\end{array}$ & $\begin{array}{l}\text { Mining } \\
\text { patterns } \\
\text { representation for the } \\
\text { information in the web } \\
\text { navigation } \\
\text { log. }\end{array}$ \\
\hline 13. & Web Mate & $\begin{array}{l}\text { Chen and Sycera } \\
1998\end{array}$ & $\begin{array}{l}\text { The user profile is } \\
\text { inferred from training } \\
\text { examples } \\
\text { effective browsing and } \\
\text { searching help. }\end{array}$ & As Proxy agent \\
\hline 14. & Speed Tracer & $\begin{array}{l}\text { Wu Yu and Ballman } \\
\text { IBM } 1998\end{array}$ & $\begin{array}{l}\text { Reconstructs the user } \\
\text { transversal paths for } \\
\text { session } \\
\text { identification by using the } \\
\text { referrer page and the } \\
\text { URL of the requested } \\
\text { page as a traversal step. }\end{array}$ & $\begin{array}{l}\text { Mining web server log } \\
\text { files }\end{array}$ \\
\hline 15. & Web Log Miner & Zaiane, 1998 & $\begin{array}{l}\text { Use data mining and } \\
\text { OLAP on treated and } \\
\text { transformed web access } \\
\text { files }\end{array}$ & Mining web logs \\
\hline
\end{tabular}

\section{CHALLENGES AND FUTURE TRENDS}

The Web stage presents new challenges to the standard data processing algorithms that job on flat information. It is seen that a number of the standard data processing algorithms are extended or new algorithms are wont to work on the net information. With explosive growth of the knowledge sources obtainable on the globe Wide net, it's become progressively necessary for users to utilize automatic tool so as to seek out the specified info resources, and to track and analyze their usage patterns.
These factors create to the need of making server aspect and consumer aspect intelligent systems that may effectively mine for knowledge. The analysis of huge diary files could be a advanced task not totally selfaddressed by existing net access analyzers. However, it's exhausting to seek out acceptable tools for analyzing raw diary information to retrieve important and helpful info. There square measure many commercially obtainable diary analysis tools, however most of them square measure unlikable by their users and regarded too slow, inflexible, expensive, tough to take care of or terribly restricted within the results they will offer. whereas some tools victimization data processing techniques to assist 
diary analyses square measure being developed, the analysis remains in its infancy. the prevailing techniques for analyzing net usage have totally different drawbacks, i.e., either large storage necessities, excessive I/O value, or quantifiability issues once further info is introduced into the analysis. Most of the presently obtainable net server analysis tools offer solely expressly and applied math info while not real helpful data for website managers. The task of mining helpful info becomes tougher once the net traffic volume is gigantic and keeps on growing. The potential of employing a web site as a knowledge assortment tool for net based mostly information systems is gigantic. This because of its interactiveness, simplicity and inconspicuousness. The results of the information mining would ideally be integrated into the dynamic web site to supply an automatic, end-to-end practical system for target selling and client relationship management. Most of the online mining tools square measure evolving and also the gift net mining techniques still have rooms for improvement to create them prevail within the web based mostly info systems. Some issues just like the want for bigger integration, quantifiability issue, and also the want for higher mining tools square measure oftentimes mentioned by several researchers. The sharpening on the mining tools in many alternative aspects is vital for the longer term development during this area:

(a)Web usage mining must handle the integration of offline data with e-business analytic tools, RDBMS, catalogs of products and services and other applications.

(b)Some improved and enhanced variables or logs should be sought that can be used for finding more natural, meaningful and useful patterns.

(c)Innovative tools are needed which will not use up too much resources or process time during the web mining process.

\section{CONCLUSION}

Designing and maintaining the web primarily based info systems, like websites, could be a real challenge. On the Web, it's a lot of easier to search out inconsistent items of knowledge than a well structured website. The study of internet usage mining and its analysis may facilitate plenty in building tools that may support the planning, development and maintenance of complicated however coherent sites. The approach is multi-disciplinary, involving software package Engineering and AI techniques. There is a robust relation between structured documents (such as internet sites) and a program; the net could be a smart candidate to experiment with a number of the technologies that are developed in software package engineering. Web Mining has been a crucial topic in data processing analysis in recent years from the posture of supporting human-specific discovery of information. the current day model of internet mining suffers from variety of shortcomings as listed earlier. As services over the net still grow (Katz 2002), there will be an unbroken ought to create them sturdy, climbable and economical. Web usage mining may be applied to raised perceive the behavior of those services, and therefore the data extracted may be helpful for numerous indices of optimizations. It is ought to study the loopholes within the analysis of internet usage patterns through existing tools and to style economical, climbable and powerful analysis tool.The event of those new tools can take care of extremely structured content like XML that may solely be processed with additional sensitive tools than raw text mining. Web usage mining (WUM) may be likely to verify if the knowledge design of an internet website is structured properly. Existing WUM tools but, don't indicate that data processing algorithms area unit getting used or offer effective graphical visualizations of the results obtained. The area unit several business tools that perform analysis on log knowledge collected from internet servers. With respect to Web Mining commercial tools, it is worth noting that since the review made in [6], the number of existing products almost doubled. Most of these tools are based on statistical analysis techniques, while only a few products actually exploit Data Mining techniques. The majority of the public and shareware tools for the analysis of Web application usage are traffic analyzers. Their functionality is limited to producing reports about site traffic, (e.g., number of visits, number of hits, page view time, etc.), diagnostic statistics, (such as server errors and page not found), referrer statistics, (such as search engines accessing the application), user and client statistics (such as user geographical region, Web browser and operating systems, etc). Only few of them also track user sessions and present specific statistics about individual users' accesses. In future, web usage mining research promises lot of space for advancements in the techniques and tools that can make some improvements in web sites specifically by focusing on the visualization of user navigation pattern by using combination technology of knowledge-based system and web-mining method. The purpose of web usage mining is to make contributions in improving the overall quality of Information Systems, to support designers during the design process and to ensure ease of use to end users.

\section{REFERENCES}

[1] O. Etzioni, The World-Wide Web: quagmire or gold mine?, Communications of the ACM, 39(11), 1996,65-68.

[2] S. K. Madria, S. S. Bhowmick, W. K. Ng, and E. Lim, Research Issues in Web Data Mining, Data Warehousing and Knowledge Discovery, 1999, 303312.

[3] J. Borges, and M. Levene, Data Mining of User Navigation Patterns', Web Usage Analysis and User Profiling, San Diego, CA, USA, 2000, 31-39.

[4] S. Chakrabarti, B. E. Dom, S. Ravi Kumar, P. Raghavan, S. Rajagopalan, A. Tomkins, D. Gibson, and J. Kleinberg,Mining the Web's Link Structure', Computer, 32(8), 1999, 60-67. Int. J. Advanced Networking and Applications 1428Volume:03 Issue:06 Pages:1422-1429 (2012) ISSN : 09750290.

[5] T. Joachims, D. Freitag, T. Mitchell, WebWatcher: A Tour Guide for the World Wide Web, Proceedings of International Joint Conference on Artificial Intelligence (IJCAI), Morgan Kaufmann, 15, 1997, 770-777.

[6] J. Srivastava, R. Cooley, M. Deshpande, P. Tan, Web usage mining: Discovery and applications of usage patterns from web data' SIGKDD Explorations newsletter, 1(2), 2000, 12-23.

[7] B. Mobasher, R. Cooley, and J. Srivastava, J. Automatic personalization based on Web usage 
mining, Communications of the ACM, 43(8), 2000, 142-151.

[8] M. Eirinaki and M. Vazirgiannis , Web mining for web Personalization, ACM Transactions on Internet Technology, 3(1), 2000, 1-27.

[9] B. Masand, M. Spiliopoulou, J. Srivastava, and O. R. Zaiane, Web Mining for Usage Patterns \& Profiles,WEBKDD02, SIGKDD Explorations, 4(2), 2002, 125-127.

[10] A. G. Buchner, M. Baumgarten, , S. S Anand, M. D. Mulvenna, and J. G. Hughes, Navigation PatternDiscovery from Internet Data, Proceedings of Web Usage Analysis and User Profiling at the International WEBKDD99 Workshop, 2000, 74- 91.

[11] S. Baron, and M. Spiliopoulou, Monitoring the Evolution of Web Usage Patterns, EWMF 2003, 181- 183.

[12] M. Spiliopoulou, Data mining for the Web, Proceedings of the Third European conference, PKDD'99, 1999, 588-589.

[13] L. Chen, and K. Sycara, WebMate: A Personal Agent for Browsing and Searching, Proceedings of the 2ndInternational Conference on Autonomous Agents, Minneapolis MN, USA, 1999, 132-139.

[14] J. I. Hong, , J. Heer, S. Waterson, and J. A. Landay, WebQuilt: A proxy-based approach to remote webusability testing, ACM Transactions on Information Systems, 19(3), 2001, 263-285.

[15] M. Koutri, N. Avouris, and S. Daskalaki, A survey on web usage mining techniques for webbasedadaptive hypermedia systems, Adaptable and Adaptive Hypermedia Systems Idea, 2004, 1-23.

[16] D. Pierrakos, G. Paliouras, C. Papatheodorou, and C. D. Spyropoulos, Web usage mining as a tool for personalization: A survey, User Modeling and UserAdapted Interaction, 13(4), 2003, 311-372. Kluwer Academic Publishers.

[17]R. Kosala, and H. Blockeel, Web Mining Research: A Survey', Machine Learning, 2(1), 2000, 1-15.

[18] R. Cooley, B. Mobasher, and J. Srivastava, Web mining: information and pattern discovery on the World Wide Web', Proceedings Ninth IEEE International Conference on Tools with Artificial Intelligence, 97(2.1), 1997, 558-567.

[19] O. R. Zaiane, Discovering Web access patterns and trends by applying OLAP and data mining technology on Web logs, Proceedings IEEE International Forum on Research and Technology Advances in Digital Libraries ADL98, IEEE Computer Society, Santa Barbara, CA,1998, 19-29.

[20] R. Cooley, Web Usage Mining: Discovery and Application of Interesting Patterns from Web data,
$\mathrm{PhD}$ thesis, Dept. of Computer Science, University of Minnesota, USA, 2000.

[21] R. S. T. Lee, and J. N. K. Liu, iJADE Web-Miner: An Intelligent Agent Framework for Internet Shopping, IEEE Transactions on Knowledge and Data Engineering, 16(4), 2004, 461- 473.

[22] B. Mobasher, H. Dai, T., Luo, and M. Nakagawa, Effective personalization based on association rule discovery from web usage data', Proceeding of the third international workshop on Web information and data management WIDM 01, 9, USA, 2001, 915

[23] F. Toolan, and N. Kusmerick, Mining Web Logs for Personalized Site Maps, Proceedings of the ThirdInternational Conference on Web Information Systems Engineering (Workshops) (WISEw'02)(WISEW '02). IEEE Computer Society, Washington, DC, USA, 2002, 232-237.

[24] L. Lu, M. H. Dunham, and Y. Meng, Discovery of Significant Usage Patterns from Clusters ofClickstream Data, Proceedings of the ACM SIGKDD Workshop on Knowledge Discovery in WebWebKDD05, 2005, Chicago, IL, USA.

[25] T. Falkowski, J. Bartelheimer, and M. Spiliopoulou, Mining and Visualizing the Evolution of Subgroups in Social Networks, Proceedings of the 2006 IEEEWICACM International Conference on WebIntelligence, 2006, 52-58.

[26] N. Labroche, M. J. Lesot, and L. Yaffi, A New Web Usage Mining and Visualization Tool', 19th IEEE International Conference on Tools with Artificial Intelligence ICTAI 2007, 1, 2007, 321328.

[27] F. Khalil, J. Li, and H. Wang, Integrating Recommendation Models for Improved Web Page Prediction Accuracy', Reproduction, 74(Acsc), Australian Computer Society, Inc. ACM International Conference Proceeding Series, Wollongong, Australia, Vol. 312, 2008, 91-100.

[28] Y. Tao, T. Hong, and Y. Su, Web usage mining with intentional browsing data, Expert Systems with Applications, 34(3), 2008, 1893-1904.

[29] O. Nasraoui, M. Soliman, E. Saka, A. Badia, and R. Germain, A Web Usage Mining Framework for Mining Evolving User Profiles in Dynamic Web Sites', IEEE Transactions on Knowledge and Data Engineering, 20(2), 2008, 202-215.

[30] F. Masseglia, P. Poncelet, M. Teisseire, and A. Marascu, Web usage mining: extracting unexpected periods from web logs, Data Mining and Knowledge Discovery, 16(1), 2008, 39-65. 